\title{
Insulin-induced GLUT4 translocation to the plasma membrane is blunted in large compared with small primary fat cells isolated from the same individual
}

\author{
N. Franck • K. G. Stenkula • A. Öst • T. Lindström • \\ P. Strålfors $\cdot$ F. H. Nystrom
}

Received: 19 March 2007 / Accepted: 12 April 2007 / Published online: 16 June 2007

(C) Springer-Verlag 2007

\begin{abstract}
Aims/hypothesis Several studies have suggested that large fat cells are less responsive to insulin than small fat cells. However, in these studies, large fat cells from obese individuals were compared with smaller fat cells from leaner participants, in effect making it impossible to draw conclusions about whether there is a causal relationship between fat cell size and insulin sensitivity. We hypothesised that small fat cells might be more insulin-responsive than large adipocytes when obtained from the same individual.

Materials and methods We developed a method of sorting isolated primary human fat cells by using nylon filters of two different pore sizes. The cells were stained to visualise DNA, which allowed discrimination from artefacts such as lipid droplets. The sorted cells were left to recover overnight, since we had previously demonstrated that this is necessary for correct assessment of insulin response.
\end{abstract}

N. Franck $\cdot$ T. Lindström $\cdot$ F. H. Nystrom

Department of Medicine and Care, Linkoping University,

Linkoping, Sweden

N. Franck $\cdot$ K. G. Stenkula $\cdot$ A. Öst $\cdot$ T. Lindström $\cdot$ P. Strålfors $•$

F. H. Nystrom

Diabetes Research Centre, Linkoping University,

Linkoping, Sweden

K. G. Stenkula $\cdot$ A. Öst $\cdot$ P. Strålfors

Department of Cell Biology, Linkoping University,

Linkoping, Sweden

F. H. Nystrom ( $\square)$

Department of Endocrinology and Metabolism,

University Hospital of Linkoping,

SE 58185 Linkoping, Sweden

e-mail: Fredrik.Nystrom@lio.se
Results We found similar amounts of the insulin receptor (IR), IRS-1 and GLUT4 when we compared small and large adipocytes from the same volunteer by immunoblotting experiments using the same total cell volume from both cell populations. Activation of IR, IRS-1 and Akt1 (also known as protein kinase B) by insulin was similar in the two cell populations. However, immunofluorescence confocal microscopy of plasma membrane sheets did not reveal any increase in the amount of GLUT4 in the plasma membrane following insulin stimulation in the large fat cells, whereas we saw a twofold increase in the amount of GLUT4 in the small fat cells.

Conclusions/interpretation Our results support a causal relationship between the accumulation of large fat cells in obese individuals and reduced insulin responsiveness.

Keywords Adipocyte · GLUT4 · Human · Insulin · Insulin receptor - Insulin resistance $\cdot$ IRS-1 $\cdot$ Primary fat cell

\section{Abbreviations \\ IR insulin receptor}

\section{Introduction}

The prevalence of obesity is increasing at an alarming rate in most parts of the world [1,2]. Obesity, in particular of the male abdominal pattern, is closely linked to diabetes, a disease characterised by greatly increased risk of macroand microvascular disease. Fat cells are among the largest cells of the body and increase tremendously in size as they differentiate from a fibroblast-like phenotype to an adipocyte by incorporating triacylglycerols into the central droplet. In parallel with this differentiation, they acquire the capacity to handle large fluxes of fatty acids across the 
plasma membrane by expression of the protein caveolin [3] to form caveolae, which are detergent-resistant invaginations of the plasma membrane, in which triacylglycerols are formed [4]. The insulin receptor (IR) is localised in caveolae [5] and when stimulated by insulin, it induces tyrosine phosphorylation of signal proteins such as the IRSs, which can relay the signal further to control metabolic and mitogenic signalling pathways in the cell [6]. The major metabolic pathways require IRS to activate Akt1 (also known as protein kinase B), a process which ultimately results in translocation of GLUT4 from intracellular vesicles to the cell surface and finally the caveolae [7], thereby allowing glucose to enter the cell. Mitogenic signalling can be transmitted through IRS [8] via the mitogen-activated protein (MAP) kinases extracellular signal-regulated kinase (ERK) 1 and 2, which control transcription of DNA through phosphorylation of different transcription factors.

Several earlier studies have suggested that large fat cells are less responsive to insulin [9-12]. However, in these studies the large fat cells were obtained from obese individuals and compared with smaller fat cells isolated from leaner participants, in effect making it impossible to draw conclusions about whether there is a causal relationship between fat cell size and insulin sensitivity [9-12].

Fat cells can be sorted according to size by techniques based on flotation and filtering [13]. However, small fat cells are very difficult to distinguish microscopically from lipid droplets formed by lysed cells, unless particular precautionary measures are taken. In this paper we present a method for sorting isolated primary human fat cells by using nylon filters of two different pore sizes. The cells were stained to visualise DNA, allowing them to be distinguished from artefacts such as lipid droplets. The sorted cells were left to recover overnight, since we have previously demonstrated that this is necessary for correct assessment of insulin response [14]. The primary aim of the study was to compare the response to insulin in large fat cells and small adipocytes taken from the same individual.

\section{Materials and methods}

Materials Rabbit anti-IRS-1 and anti-phospho-Akt1 polyclonal antibodies were from Upstate Biotechnology (Charlottesville, VA, USA). Rabbit anti-IR $\beta$, GLUT4 and goat anti-actin polyclonal antibodies were from Santa Cruz Biotechnology (Santa Cruz, CA, USA). The rabbit anti-caveolin-1 and mouse anti-phosphotyrosine antibodies (PY20) were from transduction Laboratories (Lexington, KY, USA).

Subjects Abdominal subcutaneous human adipose tissue was removed during surgery [8]. None of the participants had a diagnosis of diabetes mellitus. The five patients who donated fat tissue for the GLUT4 translocation experiment were all women undergoing surgery for gynaecological diseases; their BMIs ranged from 25 to $34 \mathrm{~kg} / \mathrm{m}^{2}$ (average: $30 \pm 4.2 \mathrm{~kg} / \mathrm{m}^{2}$ ), and they were $55 \pm 10$ years old (range $43-$ 70 years). One of these patients was operated on for cancer of the uterus (the other four had benign conditions), and was also receiving cortisone treatment for rheumatoid disease (Sjögren's syndrome). One of the other volunteers was being treated for high blood pressure. The remaining three subjects had no diagnosed medical conditions known to affect insulin sensitivity, other than their somewhat high BMI. Five of the six women who donated fat tissue for the determination of protein levels and activation of IR, IRS-1 and Akt1 by insulin were undergoing hysterectomy due to cancer of the uterus without having any signs of widespread disease, as determined by histological investigation of the greater omentum and lymphatic glands. Two of these subjects were receiving treatment for high blood pressure, and one was also taking simvastatin for hypercholesterolaemia. The sixth subject in this group was receiving gastric bypass surgery due to obesity, but had no known medical condition (age: 27 years). The BMI in these six subjects ranged from 26 to $43 \mathrm{~kg} / \mathrm{m}^{2}$ and was on average $30 \pm 6.4 \mathrm{~kg} / \mathrm{m}^{2}$; the age range was $27-83$ years (average $60 \pm 19$ years). The three subjects from whom fat was taken for determination of caveolin-1 levels had no known medical conditions and were undergoing surgery due to gynaecological bleedings $(n=2)$ or myoma of the uterus $(n=1)$. The BMI in these three subjects was $22-34 \mathrm{~kg} / \mathrm{m}^{2}$ (average $29 \pm 6.2 \mathrm{~kg} / \mathrm{m}^{2}$ ); the age range was $47-52$ years (average $50 \pm 3$ years).

Tissue sampling and sorting The adipose tissue was cleared from vascular and fibrous structures and rinsed in $0.9 \%$ (wt/ vol.) $\mathrm{NaCl}$. The fat tissue $(5-30 \mathrm{~g})$ was cut with scissors into millimetre-sized pieces and digested in equal volumes of Krebs Ringer solution $(0.12 \mathrm{~mol} / \mathrm{l} \mathrm{NaCl}, 4.7 \mathrm{mmol} / \mathrm{l} \mathrm{KCl}$, $2.5 \mathrm{mmol} / 1 \mathrm{CaCl}_{2}, 1.2 \mathrm{mmol} / 1 \mathrm{MgSO}_{4}, 1.2 \mathrm{mmol} / 1 \mathrm{KH}_{2} \mathrm{PO}_{4}$ ) containing $20 \mathrm{mmol} / 1 \mathrm{HEPES}, \mathrm{pH} 7.4,3.5 \%$ (wt/vol.) fatty acid-free bovine serum albumin, $200 \mathrm{nmol} / \mathrm{l}$ adenosine, $2 \mathrm{mmol} / \mathrm{l}$ glucose and $260 \mathrm{U} / \mathrm{ml}$ collagenase (Worthington, Lakewood, NJ, USA) for $1.5 \mathrm{~h}$ at $37^{\circ} \mathrm{C}$ in a water bath subjected to agitation. After collagenase digestion, the adipocytes were separated from connective tissue debris by filtering through a gauze web. The adipocytes were then washed (at $40 \%$ cells by volume) in the Krebs Ringer solution containing $20 \mathrm{mmol} / \mathrm{l}$ HEPES, $\mathrm{pH} 7.4,1 \%$ (wt/ vol.) fatty acid-free bovine serum albumin (Roche, Mannheim, Germany), $200 \mathrm{nmol} / 1$ adenosine and $2 \mathrm{mmol} / 1$ glucose and kept in a water bath that was subjected to agitation at $37^{\circ} \mathrm{C}$ until separation.

The separation of isolated adipocytes into small and large fractions was achieved using nylon filters (Millipore, 
Billerica, MA, USA). To collect the small adipocyte fraction, $1 \mathrm{ml}$ of fat cells was suspended in $45 \mathrm{ml}$ of fresh medium and gently run through a filter with a pore size of $60 \mu \mathrm{m}$. The cells that passed through the filter constituted the small adipocytes. The adipocytes that were trapped on the $60 \mu \mathrm{m}$ filter were passed through a second filter with a pore size of $120 \mu \mathrm{m}$. Those that were retained by this second nylon filter were collected and constituted the fraction of large adipocytes. After separation, each fraction was allowed to recover overnight at $37^{\circ} \mathrm{C}, 10 \% \mathrm{CO}_{2}$ in Krebs Ringer solution mixed with an equal volume of DMEM, pH 7.5, containing $25 \mathrm{mmol} / 1$ of glucose, $50 \mathrm{UI} / \mathrm{ml}$ of penicillin, $50 \mathrm{~g} / \mathrm{ml}$ of streptomycin, $200 \mathrm{nmol} / \mathrm{l}$ of phenyl-isopropyl-adenosine, $7 \%$ (wt/vol.) fatty acid-free bovine serum albumin and $25 \mathrm{mmol} / \mathrm{l}$ of HEPES. Aliquots from each fraction were stained using Mayer's Haematoxylin to visualise their nuclei, thereby distinguishing adipocytes from other particles such as lipid droplets. The cell diameters of the adipocytes were measured using Scion Image (Scion Corporation, Frederick, MD, USA). Representative pictures were taken at 10 to $20 \times$ magnification using an E800 Eclipse Microscope (Nikon, Tokyo, Japan) or a DMRXA2 (Leica, Wetzlar, Germany) microscope.

SDS-PAGE and immunoblotting After overnight incubation of the two cell populations, each fraction was treated with or without $10 \mathrm{nmol} / 1$ of insulin for $10 \mathrm{~min}$ at $37^{\circ} \mathrm{C}$ in a water bath subjected to agitation. The cell incubations for immunoblotting were terminated by separating cells from medium by centrifugation at $5,000 \times g$ through dinonylphthalate. To minimise post incubation changes in signalling and protein modifications the cells were immediately dissolved in SDS and $\beta$-mercaptoethanol with protease and protein phosphatase inhibitors, frozen within $10 \mathrm{~s}$ and thawed in boiling water. Equal amounts of cells as determined by lipocrit, which is total cell volume, were subjected to SDS-PAGE and immunoblotting. The volume of cells per volume of medium was adjusted so that the lipocrit in both the small and large fat cells was within 0.095 to 0.105 in each experiment. After SDS-PAGE and electrotransfer, the membranes were incubated with the indicated antibodies. The secondary horseradish peroxidaseconjugated anti-IgG antibody was visualised with the ECL+ reagent (Amersham Biosciences, Amersham, UK) and evaluated by chemiluminescence imaging (Las 1000; Image-Gauge, Fuji, Tokyo, Japan).

Immunofluorescence confocal microscopy Plasma membrane sheets were prepared as described $[15,16]$ and fixed in phosphate buffer $\left(10 \mathrm{mmol} / 1 \mathrm{Na}_{2} \mathrm{HPO}_{4}, 150 \mathrm{mmol} / \mathrm{l} \mathrm{NaCl}\right.$, $\mathrm{pH}$ 7.5) containing 3\% (vol./vol.) paraformaldehyde for $30 \mathrm{~min}$ at room temperature. After blocking in bovine serum albumin, membranes were incubated with the indicated antibodies. The primary antibody was detected with a fluorescent secondary antibody (highly crossabsorbed Alexa fluor 488; diluted 1:300), from Molecular Probes (Carlsbad, CA, USA) by fluorescence microscopy with a DMIRE2 microscope (Leica). Labelling against GLUT4 was measured in 40 cells from each patient (10 in each adipocyte fraction, with or without insulin, respectively) with the same microscopic and software settings in all membranes. No labelling was observed in the absence of
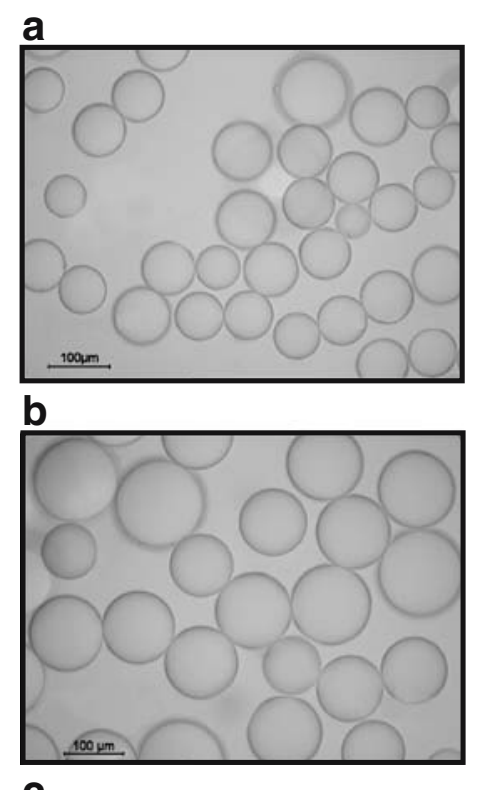

C

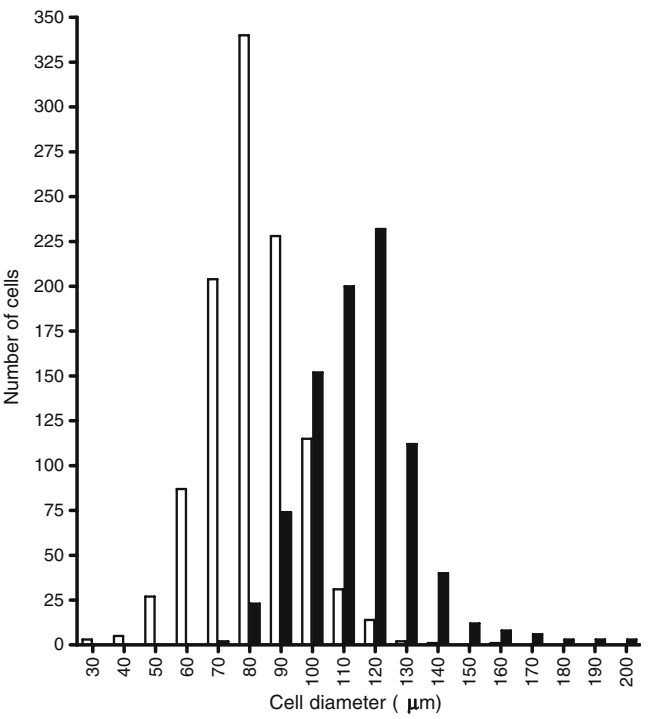

Fig. 1 Primary human fat cells were sorted using nylon filters and the cell diameter was measured by microscopy. a Small cells, average diameter $81.3 \pm 14 \mu \mathrm{m}$; b large cells, average diameter $114 \pm 17 \mu \mathrm{m}$. Scale bar: $100 \mu \mathrm{m}$. c Graph showing the size distribution of 870 large (filled bars) and 1,058 small (open bars) cells obtained after sorting of fat cells from six individual patients 


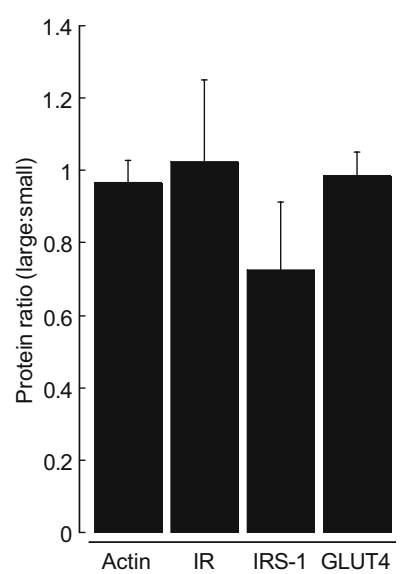

Fig. 2 The amount of $\beta$-actin, IR, IRS-1 and GLUT4 in whole cell lysates from sorted small and large primary human fat cells. Fat cells were sorted and allowed to recover overnight. Equal cell volumes, consisting of either large or small fat cells, were subjected to SDSPAGE, transferred to polyvinylidene fluoride (PVDF) membranes and immunoblotted with anti- $\beta$-actin, IR, IRS- 1 and GLUT4 antibodies. The blots were normalised to the amount of staining in the small adipocyte population, i.e. results are presented as a ratio of the intensity in large:small fat cells in each individual, to enable comparisons between samples that were loaded onto different gels. There was no statistically significant difference in the amount of $\beta$ actin, IR, IRS-1 or GLUT4 in the two cell-size populations $(n=4)$

the primary antibody. Fluorescence intensity was measured with Scion Image.

Ethics The study was approved by the Human Ethics Committees of Linkoping University and performed in accordance with the Declaration of Helsinki. Informed consent was obtained from all participating patients.
Statistical analysis Statistical calculations were performed with StatView 4.5 (Abacus Concepts, Berkeley, CA, USA) software. Comparisons within and between groups were done with Student's paired and unpaired two-tailed $t$ test. Unless otherwise stated, values are given as means \pm SD. Statistical significance was considered to be given at the $5 \%$ level $(p \leq 0.05)$.

\section{Results}

The sorting technique allowed separation of two groups of cells with a significant difference in diameter distribution (Fig. 1a-c; note that the staining of DNA is not clearly visible at this low magnification). Small fat cells were on average $81.3 \pm 14 \mu \mathrm{m}$ in diameter (5th percentile $58 \mu \mathrm{m}$, 95th percentile $102 \mu \mathrm{m}$ ) whilst large fat cells were $114 \pm 17$ diameter (5th percentile $90 \mu \mathrm{m}, 95$ th percentile $142 \mu \mathrm{m}$ ). The mean diameter difference of the small and large fat cell populations was $35.3 \mu \mathrm{m}(95 \%$ CI $25.3-45.3 \mu \mathrm{m}, p=$ 0.0003 in paired $t$ test for six separate experiments).

There was no difference in amounts of $\beta$-actin, IR, IRS-1 or GLUT4 in the two cell populations, as quantified with immunoblotting of cell lysates (Fig. 2). Small and large fat responded similarly to insulin with regard to activation of the IR, IRS-1 and phosphorylation of Akt1 (Fig. 3).

Immunofluorescence confocal imaging of labelled GLUT4 at the plasma membrane allowed us to quantify the amount of this glucose transporter per surface area of plasma membrane. Interestingly, insulin induced a doubling a

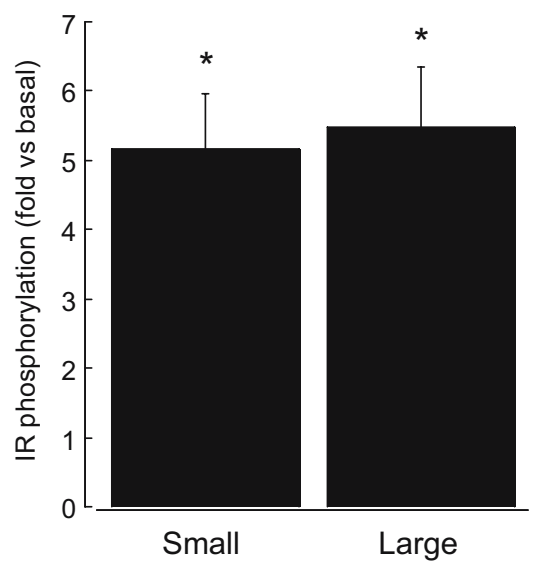

b

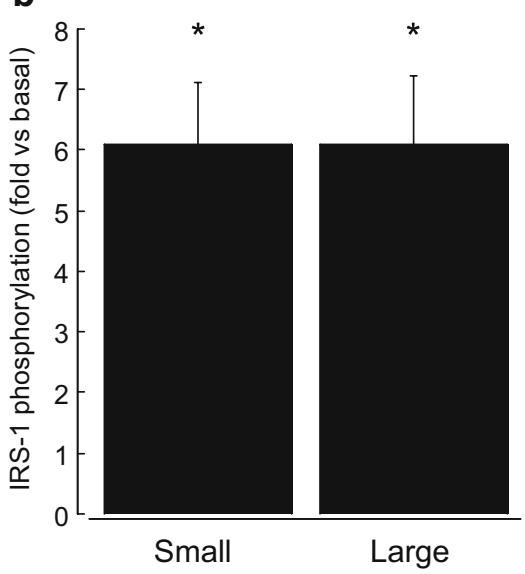

C

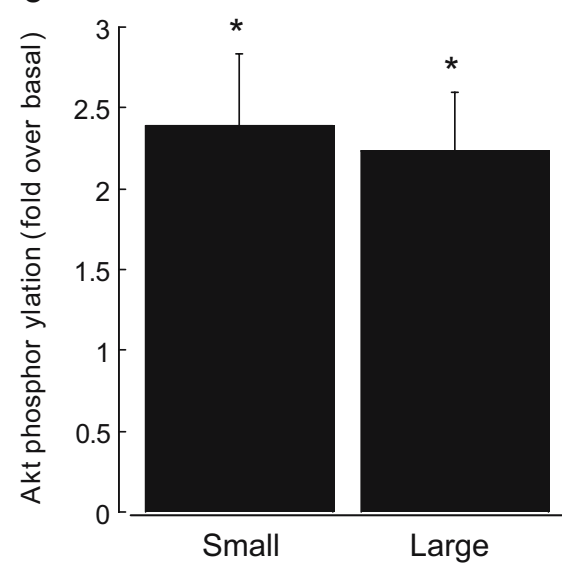

Fig. 3 Insulin-induced activation of IR, IRS-1 and Akt1 in sorted small and large primary human fat cells. Primary human fat cells were sorted into two cell populations, small and large, and allowed to recover overnight. The cells were treated with or without $10 \mathrm{nmol} / 1$ insulin for $10 \mathrm{~min}$. An equal amount of cell volume was subjected to SDS-PAGE, transferred to poly vinylidene fluoride (PVDF) membranes and immunoblotted with anti-phosphotyrosine for IR (a) and IRS-1 (b) or anti-

phospho-Akt1 antibodies (c). The quantification of the immunoblot was normalised to the amount of staining in non-stimulated adipocytes, in order to enable comparisons between experiments that were loaded on different gels. There was no statistically significant difference in the effect of insulin when the responses in small and large fat cells were compared $(n=4) .{ }^{*} p<0.05$ compared with basal, non-insulin stimulated phosphorylation in either small or large fat cells 
a

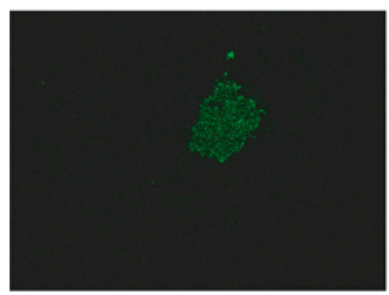

C

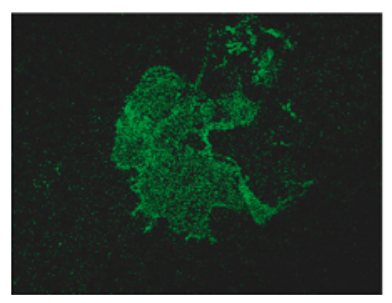

d

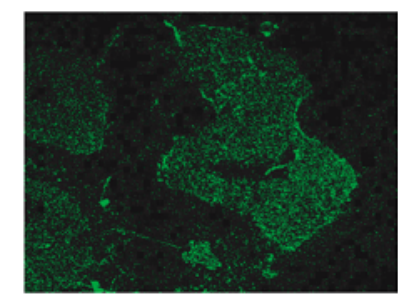

b
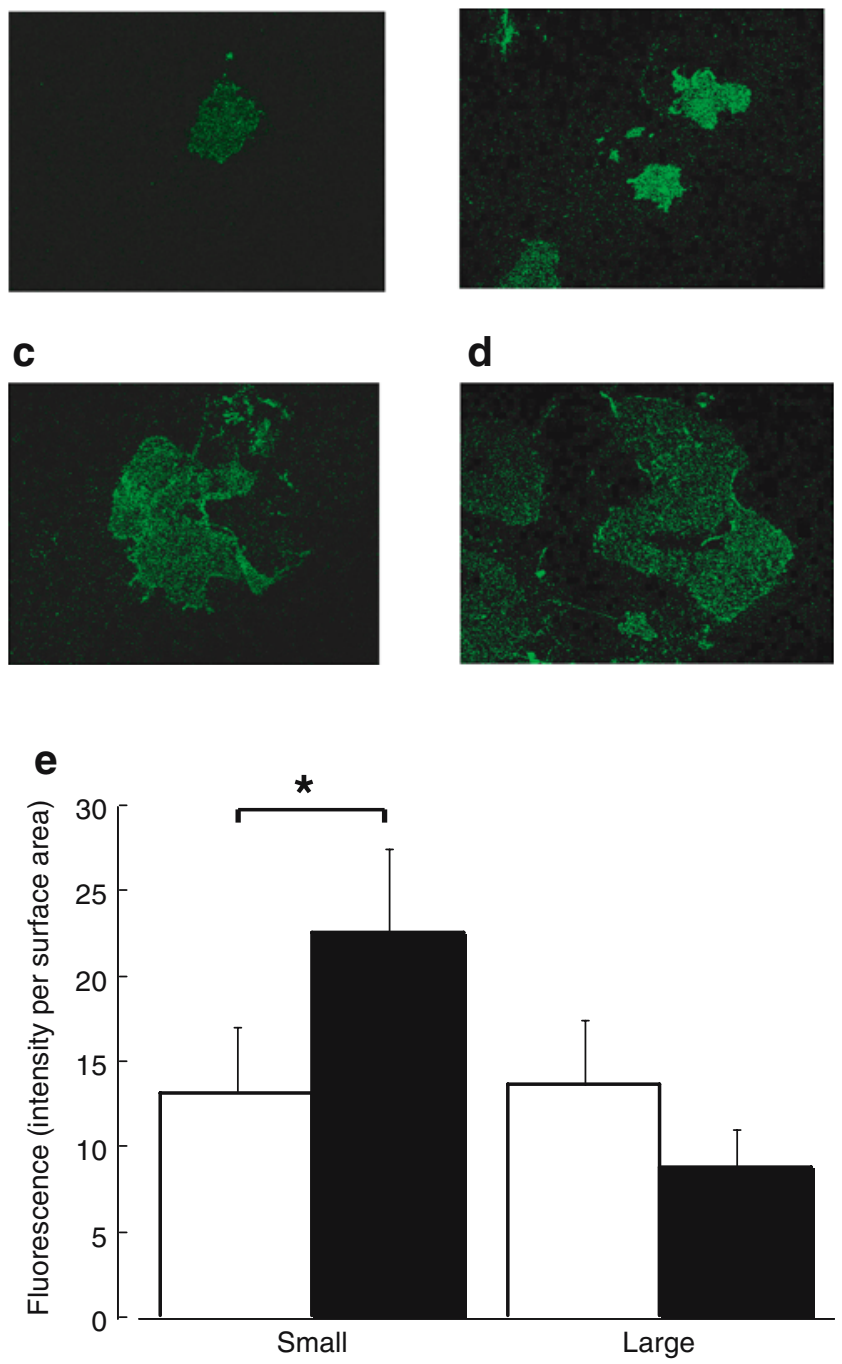

Fig. 4 Insulin induces increased translocation of GLUT4 to the plasma membrane in small, but not in large primary human fat cells. Primary human fat cells were sorted into two cell populations, small and large, and allowed to recover overnight. The cells were treated with or without $10 \mathrm{nmol} / \mathrm{l}$ insulin for $30 \mathrm{~min}$ and plasma membrane sheets were prepared from the fat cells for immunofluorescence confocal microscopy and labelling with anti-GLUT4 antibodies. a Small cells, basal; b small cells, insulin-stimulated; c large cells, basal; d large cells, insulin-stimulated. e The fluorescence intensity (mean pixel density per area unit) of the secondary antibodies was quantified from five individual experiments. Filled bars, with insulin treatment; open bars, without insulin treatment. ${ }^{*} p<0.05$

of GLUT4 density in the small fat cells, whilst in the larger adipocytes from the same subjects there was no response to insulin stimulation (Fig. 4a-e). The patient on cortisone treatment (see "Materials and methods" section), a drug known to induce insulin resistance, displayed a fourfold increase of GLUT4 in the plasma membrane in the small cells following insulin stimulation and no change of GLUT4 in the plasma membrane in large fat cells.
Caveolin-1 levels increase as fat cells differentiate from preadipocytes and increase in size [17]. However, quantification of caveolin-1 in the plasma membrane using immunofluorescence microscopy revealed that both cell size populations had similar amounts of caveolin-1 per surface area (Fig. 5).

\section{Discussion}

We found that insulin did not induce an increase in GLUT4 at the plasma membrane in large fat cells. However, in the smaller fat cells from the same subjects, we observed, on average, a doubling of GLUT4 at the cell surface, which is similar to levels shown by us earlier in primary human fat cells incubated overnight [8]. This interesting finding suggests that glucose uptake mainly takes place in smaller fat cells in the fat tissue and points to a causal relationship between the accumulation of large fat cells and reduced insulin sensitivity in obese subjects. This provides further insight into the mechanism of action of glucose-lowering drugs that are activators of the peroxisome proliferatoractivated receptor $\gamma$, which increase insulin sensitivity in humans whilst also inducing a relative increase in the number of small adipocytes in the fat tissue [18]. Our method did not yield large enough quantities of fat cells to allow determination of glucose uptake. Since it is possible that increased glucose uptake depends on both translocation and activation $[19,20]$ of GLUT4, we cannot exclude the possibility that some increase in glucose uptake still takes place in response to insulin in large fat cells. The fact that there was no difference with regard to activation of the IR, IRS-1 and Akt1 in the two adipocyte populations strongly

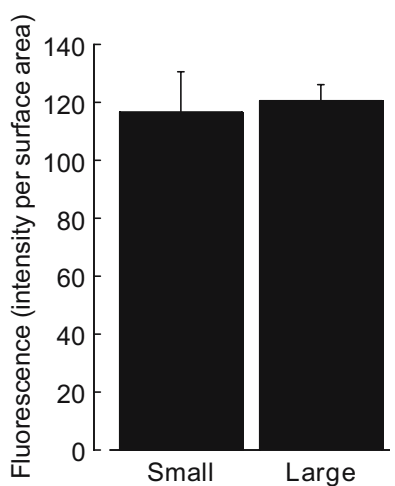

Fig. 5 The amount of caveolin-1 in the plasma membrane is similar in small and large fat cells isolated from the same subject. Primary human fat cells were sorted into two cell populations, small and large, and allowed to recover overnight. Plasma membrane sheets were prepared from the fat cells for immunofluorescence confocal microscopy and labelling with anticaveolin-1 antibodies. The fluorescence intensity (mean pixel density per area unit) of the secondary antibodies was quantified from three individual experiments. The intensity was similar in the two cell populations. Comparison was by paired $t$ test, $p>0.8$ 
argues against the possibility that, due to traumatising effects of the sorting procedure, large fat cells were more fragile and hence responded less strongly to insulin in terms of GLUT4 translocation. Indeed, some of the cells in the fraction of small cells had larger diameters then the mesh pores, suggesting that fat cells are quite flexible and may squeeze through square pores without rupturing, even though the cell diameter is larger than the pore width.

Our findings of functional differences in large and small fat cells from the same subjects are in line with a recent paper, in which substantial differences in mRNA expression for different proteins were found in large and small fat cells isolated from the same subjects [13]. In that paper Jernas et al. used a different technique from ours for sorting the cells, namely one involving filters as well as differences in flotation rate; in addition, no staining was done prior to microscopic determination of cell size distribution [13].

We found no differences with regard to insulin-induced phosphorylation of Akt1 in small compared with large fat cells. Insulin achieves antilipolytic control of fat cells through activation of Akt1; our findings thus suggest that this fundamental metabolic action of insulin is still functional in large fat cells, at least at this relatively high insulin concentration. It is quite possible, however, that further studies of insulin-induced Aktl activation might reveal a different dose-response relationship in large and small fat cells. To make such analyses possible, it would be necessary to further develop our method to allow severalfold more insulin doses to be investigated at the same time. Our method for sorting fat cells is less tedious than that described by Jernas et al. [13], but does not yield large enough amounts of sorted fat cells to allow assessment of the response to multiple doses of insulin.

It should be emphasised that for the immunoblotting a similar volume of cells was subjected to the SDS-PAGE separation. This means that the insulin response to activation of the IR, IRS-1 and Akt1 would be similar in a hypothetical tissue consisting of either small or large fat cells. Another common standardisation method for immunoblotting is to normalise to the amount of protein in the lysate. However, we found no difference in the amount of $\beta$-actin, a protein often used as reference for protein levels, in large and small fat cells. This strongly suggests that using normalisation for total protein level in each lysate would yield the same results as using cell volume. Indeed, the amounts of the IR, IRS-1 and GLUT4 were all similar in large and small fat cells, corroborating the study of mRNA levels by Jernas et al. [13].

In conclusion, the finding of blunted translocation of GLUT4 to the plasma membrane in response to insulin supports a causal relationship between the accumulation of large fat cells in obese subjects and the related resistance to insulin-induced glucose uptake. Further studies of the mechanisms behind fat cell hypertrophy could potentially reveal pharmacological means to reduce fat cell size and hence to reduce the burden of insulin resistance in conditions such as type 2 diabetes, dyslipidaemia and hypertension.

Acknowledgements We thank K. Crafoord, P. Sandström, B. Lönnberg, S. Halili and G. Andreescu for supplying fat tissue obtained during surgery. Financial support was from Lions Foundation, Gamla Tjänarinnor, Östergötland County Council, Swedish Medical Society, University Hospital of Linkoping Research Funds, Lars Hierta and the Diabetes Research Centre.

Duality of interest statement The authors declare that there are no potential conflicts of interest with regard to this paper.

\section{References}

1. Zimmet P, Shaw J, Alberti KG (2003) Preventing type 2 diabetes and the dysmetabolic syndrome in the real world: a realistic view. Diabet Med 20:693-702

2. Singh R, Shaw J, Zimmet P (2004) Epidemiology of childhood type 2 diabetes in the developing world. Pediatr Diabetes 5:154-168

3. Kandror KV, Stephens JM, Pilch PF (1995) Expression and compartmentalization of caveolin in adipose cells: coordinate regulation with and structural segregation from GLUT4. J Cell Biol 129:999-1006

4. Ost A, Ortegren U, Gustavsson J, Nystrom FH, Strålfors P (2005) Triacylglycerol is synthesized in a specific subclass of caveolae in primary adipocytes. J Biol Chem 280:5-8

5. Thorn H, Stenkula KG, Karlsson M et al (2003) Cell surface orifices of caveolae and localization of caveolin to the necks of caveolae in adipocytes. Mol Biol Cell 14:3967-3976

6. Nystrom FH, Quon MJ (1999) Insulin signalling: metabolic pathways and mechanisms for specificity. Cell Signal 11:563-574

7. Karlsson M, Thorn H, Parpal S, Strålfors P, Gustavsson J (2002) Insulin induces translocation of glucose transporter GLUT4 to plasma membrane caveolae in adipocytes. FASEB J 16:249-251

8. Stenkula KG, Said L, Karlsson M et al (2004) Expression of a mutant IRS inhibits metabolic and mitogenic signalling of insulin in human adipocytes. Mol Cell Endocrinol 221:1-8

9. Weyer C, Foley JE, Bogardus C, Tataranni PA, Pratley RE (2000) Enlarged subcutaneous abdominal adipocyte size, but not obesity itself, predicts type II diabetes independent of insulin resistance. Diabetologia 43:1498-1506

10. Smith U (1972) Studies of human adipose tissue in culture. I. Incorporation of glucose and release of glycerol. Anat Rec 172:597-602

11. Salans LB, Knittle JL, Hirsch J (1968) The role of adipose cell size and adipose tissue insulin sensitivity in the carbohydrate intolerance of human obesity. J Clin Invest 47:153-165

12. Salans LB, Dougherty JW (1971) The effect of insulin upon glucose metabolism by adipose cells of different size. Influence of cell lipid and protein content, age, and nutritional state. J Clin Invest 50:1399-1410

13. Jernas M, Palming J, Sjoholm K et al (2006) Separation of human adipocytes by size: hypertrophic fat cells display distinct gene expression. FASEB J 20:1540-1542

14. Danielsson A, Ost A, Lystedt E et al (2005) Insulin resistance in human adipocytes occurs downstream of IRS1 after surgical cell isolation but at the level of phosphorylation of IRS1 in type 2 diabetes. FEBS J 272:141-151 
15. Robinson LJ, Pang S, Harris DS, Heuser J, James DE (1992) Translocation of the glucose transporter (GLUT4) to the cell surface in permeabilized 3T3-L1 adipocytes: effects of ATP, insulin, and GTPgS and localization of GLUT4 to clathrin lattices. J Cell Biol 117:1181-1196

16. Gustavsson J, Parpal S, Karlsson M et al (1999) Localisation of the insulin receptor in caveolae of adipocyte plasma membrane. FASEB J 13:1961-1971

17. Scherer PE, Lisanti MP, Baldini G, Sargiacomo M, Mastick CC, Lodish HF (1994) Induction of caveolin during adipogenesis and association of GLUT4 with caveolin-rich vesicles. J Cell Biol 127:1233-1243

18. de Souza CJ, Eckhardt M, Gagen K et al (2001) Effects of pioglitazone on adipose tissue remodeling within the setting of obesity and insulin resistance. Diabetes 50:1863-1871

19. Furtado LM, Somwar R, Sweeney G, Niu W, Klip A (2002) Activation of the glucose transporter GLUT4 by insulin. Biochem Cell Biol 80:569-578

20. Michelle Furtado L, Poon V, Klip A (2003) GLUT4 activation: thoughts on possible mechanisms. Acta Physiol Scand 178:287-296 